\title{
Behavioral insurance: Theory and experiments
}

\author{
Andreas Richter • Jörg Schiller • Harris Schlesinger
}

Published online: 27 April 2014

(C) Springer Science+Business Media New York 2014

\begin{abstract}
Risk and insurance" provides an illustrative set of decisions made in the presence of uncertainty. As behavioral models become more integrated into economics and finance, many of their effects are illustrated quite well within insurance markets. Especially noteworthy are the complementary roles of theory and experiments. This article reviews the interactive role of experiments and theory in analyzing insurance demand from a behavioral perspective. We pay special attention to several models of underinvestment in insurance or in other risk-mitigation markets.
\end{abstract}

Keywords Adverse selection · Ambiguity aversion · Annuity puzzle · Behavioral economics · Catastrophe insurance · Genetic tests · Inequality aversion · Laboratory experiment $\cdot$ Loss aversion $\cdot$ Non-expected utility

JEL Classification $\mathrm{C} 91 \cdot \mathrm{D} 03 \cdot \mathrm{D} 11 \cdot \mathrm{D} 14 \cdot \mathrm{D} 81 \cdot \mathrm{D} 82 \cdot \mathrm{D} 91 \cdot \mathrm{G} 22 \cdot \mathrm{I} 12$

"What do economic theory and experimental economics have to contribute to one another, and how can we shape their interaction to enhance these contributions?" Samuelson (2005, p. 65)

Consider a two-state model with payoffs in units of satisfaction labeled as "utility." Three utility lotteries are available with the state contingent payoffs $A=(10,0)$,

\footnotetext{
A. Richter

Institute for Risk Management and Insurance, Ludwig-Maximilians University,

Schackstr. 4, 80539 Munich, Germany

e-mail: richter@lmu.de

J. Schiller

Institute for Health Care \& Public Management, University of Hohenheim,

Fruwirthstr. 48, 70593 Stuttgart, Germany

e-mail: j.schiller@uni-hohenheim.de

H. Schlesinger $(\bowtie)$

Department of Finance, University of Alabama, Tuscaloosa, AL 35487-0224, USA

e-mail: hschlesi@cba.ua.edu
} 
$B=(0,10)$ and $C=(4,4)$. Regardless of one's beliefs about the state probabilities, an expected-utility maximizer would never prefer lottery $C$, given a choice of the three lotteries. Of course, we can model alternative theories about preferences where lottery $C$ is a perfectly rational choice, where "rational" is defined to imply that the choice does not contradict a particular theory. Alternatively, if we observe someone choosing lottery $C$, we might label the individual as "irrational," or we might simply attribute the choice as a "mistake" that would not repeat itself too often. In addition, we might prescribe various remedies (e.g. better education, better "framing" of the decision, allowing the subject to learn by experience, etc.) so that such "mistakes" are mitigated in future choices.

As Postlewaite and Schmeidler (2012) point out, in any revealed-preference approach the optimal choice is the one that was made. Of course, one important factor is the nature of the observation. In the field, it is not usually possible to understand all of the situational factors that are taken (or not taken) into consideration. Although such extraneous factors might be controlled in the laboratory, subjects are typically aware of their setting and one cannot be certain if the choices made would concur with isomorphic real-world decisions.

Risk-taking decisions can be highly complex and highly dependent on the specific situation of each decision maker. "Rational decisions" made within the contextual model of expected utility theory (EUT) are often described as "normative." Although EUT has some predictive power, it also seems to have many contradictions to predicted outcomes. Behavioral models attempt to add various cognitive factors into the process. Some of these might be simplifications; some might be awareness of a social context; and some might be recognition of one's own emotions, hopes and fears.

For example, how do individuals deal with complex situations? Do they recognize the complexity, and if so, how do they make their choices? If they somehow bypass the complexity, do they only consider certain salient aspects of the decision while making their choices? That is, do they make decisions that one might consider to be "boundedly rational"? For a researcher, it is hard to isolate the extent to which observed decisions have been driven by perceptions versus driven by preferences. ${ }^{1}$ Faced with identical complex situations, individuals often act quite differently. Indeed, even the same individual might react differently based on the exact framing of the situation, or based on one's mood, or based on observed decisions being made by others. Ideally, one theory with sufficient degrees of freedom could explain these observed decision variations. However, the last few decades of experimental and empirical research indicate that one size may not fit all, meaning that we have to consider that several latent behavioral processes might exist and, consequently, no one theory is likely to explain observed behavior (Harrison and Rutström 2009). Nevertheless, theoretical models still are the basis for most experimental or empirical research.

Insurance markets are particularly amenable to the observation of risk-taking decisions. Indeed, the area of "risk and insurance," broadly defined, serves as an illustrative set of decisions made in the presence of uncertainty. As the new spirit of

\footnotetext{
${ }^{1}$ Fortunately, there are approaches to reduce the uncertainty related to the data from observed choices in the field. An integral part of revealed-preference analysis is often to measure expectations, which need not be "rational" (Manski 2004). Harrison and Martinez-Corea (2012) discuss related problems of estimating model parameters for weighting, utility and value functions. For an interesting perspective on "rationality" in a laboratory setting, see Postlewaite and Schmeidler (2012).
} 
"behavioralism" becomes an integral part in the field of insurance, it is important to give this stream of research a platform. Both the Center for the Economic Analysis of Risk (CEAR) at Georgia State University and the Munich Risk and Insurance Center (MRIC) initiated conferences on "Behavioral Insurance" in 2011. These two Centers have committed to working jointly to provide support to research in this direction.

This special issue of the Journal of Risk and Uncertainty contains four papers from a joint CEAR/MRIC Behavioral Insurance Workshop, which took place in Munich in December 2012. ${ }^{2}$ Although the four papers in this issue examine quite different problems, each is concerned with how factors that are often ignored under EUT might decrease participation in insurance markets as well as in other types of risk-sharing or risk-mitigation markets. Two of the papers are theoretical while the other two are mostly experimental.

\section{From expected utility to behavioral approaches}

EUT has long been the cornerstone for normative models of insurance demand under risk, and also provides a common base of comparison for various positive models. Indeed, pioneers in the early days of insurance economics, such as Karl Borch (1968), often referred to EUT under risk aversion as "the Bernoulli Principle," in homage to the famous treatise by Daniel Bernoulli (1738). Results from EUT models are still used to explain many real-world transactions, such as the design of insurance contracts, which may entail deductibles and/or proportional risk sharing. ${ }^{3}$ Indeed, various non-EUT models often support the results derived under EUT; but at other times they do not. A first attempt at collecting such comparisons was Machina (1995).

Of course, EUT and its founding axioms have been heavily challenged. But another important stream of literature stems from doubts regarding the positive explanatory power of EUT. Actual contractual features, survey answers and experimental results are often inconsistent with expected utility. Many extensions of the standard EUT model give additional degrees of freedom and may have a higher predictive power for some individuals. However, the entangled relationship between perceptions and preferences remains.

As controlled experiments became more common in economics, doubts about the general explanatory power of EUT and about rational-behavior models were reinforced (Starmer 2000). The appealing feature of laboratory experiments is that they can control the decision-making environment. This artificial environment is both boon and bane. Although we can control the complexity of the decision-making environment, and can thus focus more on preferences, we might not tend to trust information gleaned about preferences when such information is derived from artificial (or unrealistic) situations.

\footnotetext{
2 The local organizer and head of the scientific committee was the MRIC director Andreas Richter. Harris Schlesinger and Jörg Schiller, together with Richter, are Guest Editors for this special issue and handled the submissions in close collaboration with the Editor-in-Chief Kip Viscusi. Since Andreas Richter was also a potential contributing author, he was not part of the review process. The Editors specially thank the many referees who showed a strong commitment to the tight time schedule and helped to further improve the submitted papers with their comments.

${ }^{3}$ Many models have tried to extend these results within EUT by adding additional influences, such as information asymmetries; see for example Gollier (1996) and Drèze and Schokkaert (2013).
} 
Analyzing the transferability from laboratory experiments to the field is, fortunately, a real concern of many experimentalists (Harrison and List 2004). However, experimental evidence and "behavioral economics" need not be narrowly defined on positive theories differing from EUT. Instead, such research might best be viewed as an examination of models describing the actual behavior of individuals, including both alternatives to and modifications of standard EUT.

Many basic observations are still in need of further explanation. For example, do people tend to behave in a manner that is more risk averse or less risk averse than theory predicts? Various authors have come to very different conclusions (Rabin 2000; Andersen et al. 2008; Sydnor 2010; Cohen and Einav 2007; Laury et al. 2009). And the literature is filled with questions based on this very notion, such as the famous equitypremium puzzle of Mehra and Prescott (1985).

Moreover, many competing theories are hard to test for directly. Can we ever really know how individuals set reference points, if we want to test other aspects of prospect theory? Or can we empirically disentangle ambiguity beliefs from ambiguity preferences? Will theory help us design experiments or will it work in reverse? The importance of this interaction between theory and experiments is the main focus of Samuelson (2005), who espouses the complementary nature of these two approaches. In their own separate ways, both approaches need to abstract from reality.

Apart from general theories of decision making under risk, behavioral insurance has some idiosyncrasies that make it a topic of special interest within behavioral economics and behavioral finance. Two important factors contribute to this interest in insurance. First, insurance markets constitute a specific institutional environment, which necessitates studies in their own right. Insurance contracts have very particular features. The second important factor is the psychological and economic evidence that indicates that individuals might react differently towards decisions within the domain of insurance compared to decisions made in other domains.

Insurance markets differ in many ways from the markets for other types of goods. Insurance contracts are aleatory contracts: one purchases, in essence, a promise from the insurer to pay for contingent events. Risk aversion in monetary stakes as well as a belief that the insurer will pay as promised is what drives the demand for insurance. In addition, insurance contracts require "uberrimae fidei" ("utmost good faith"), which is a higher standard of disclosure from both parties than most other contracts. The role of information is more important in insurance markets than in most other markets. This is why many, if not most, studies of adverse selection and moral hazard are focused on insurance markets (e.g. Rothschild and Stiglitz 1976; Chiappori and Salanié 2000; Finkelstein and McGarry 2006; Einav et al. 2010). These two features of insurance contracts also (unfortunately) beget various types of insurance fraud (e.g. Crocker and Morgan 1998; Picard 1996).

Even when claims are not fraudulent, insurable damages are oftentimes less than fully transparent. For instance, liability claims often include "non-economic damages," which can be quite subjective. Indeed, the legal system is often used to limit —or at least to better delineate - such types of damages. For example, tort regulation has very definitive effects on insurance markets; see, among others, Viscusi and Born (2005).

Insurance contracts are highly complex and mostly incomplete. In this situation, the fact that individuals are insured may lead to spillover effects in related health care or repair markets (Nell et al. 2009). An important role of behavioral insurance is to explain 
some of the discrepancies found in studies of insurance markets through new behavioral theories or modifications of classical theory. Some of the papers included in this special issue have exactly this purpose.

The other important reason why behavioral insurance, at least to some extent, needs to be studied as an independent field is the difference in decision behavior regarding insurance choices vs. other risky choices. Psychological evidence suggests that individuals perceive risks differently in various contexts and also adapt different risk management solutions (Slovic 1987). For instance, it has been shown that subjects in laboratory experiments act in a more risk averse manner when confronted with an insurance decision than when the decision is framed in some alternative context (e.g. Schoemaker and Kunreuther 1979; Hershey and Schoemaker 1980; Kusev et al. 2009). While there also is some evidence to the contrary (Wakker et al. 1997), the findings seem to be especially robust in settings which closely resemble real-world insurance markets (see Hershey and Schoemaker 1980 for a general result and Buckley et al. 2012 for an application to health insurance). Einav et al. (2012) further confirm this hypothesis using field data on people's choices of different insurance policies and their investment decisions in 401(k) plans. Barseghyan et al. (2011) go even further to show that risk attitudes might differ between different insurance policies.

The fact that results for insurance contexts differ significantly from those for other contexts highlights the importance of establishing insurance as a field of behavioral research. Since it is common to use insurance data for testing behavioral models (e.g. Sydnor 2010; Barseghyan et al. (2013)), it is imperative for behavioral insurance to establish to what degree findings made within an insurance context can be extrapolated to other types of decisions. Similarly, behavioral insurance has the task of confirming whether or not behavioral observations from other fields also apply within a specific insurance context.

Insurance decisions are perhaps the most basic type of choice under uncertainty. They are arguably one of the regularly encountered real-life choices which come closest to those posed by theoretical models. Thus, insurance markets can often be fruitful in gleaning insight into the validity of such theoretical models, particularly as first evidence. But many questions remain. Can we realistically model an aversion to large real-world financial losses in a laboratory setting? Will standard ceteris paribus assumptions hold for decisions made in the field? Or even if such decisions are made in isolation from other contemporaneous decisions, will the mere existence of other risks create a type of background noise that affects choices? And while we can control probabilities in any laboratory experiment in a de jure sense, can we really control them de facto? Indeed there are many possible associated epistemic risks over which the experimenter really has no control: Are the coins really fair? Are my answers truly held confidential? Are my choices meant to reflect my intelligence, as opposed to my tastes?

\section{Contribution of the special issue}

The four papers included in this special issue of the Journal of Risk and Uncertainty are good examples of the broad scope of behavioral research in the area of insurance. They deal with various relevant puzzles in insurance markets, all focused in some way at seeming under-activity in protecting oneself against loss. 
The first paper, by Friedl et al. (2014), deals with the rather low demand for disaster insurance, e.g. for hurricanes and floods, even when insurance premiums are subsidized. The literature offers many different explanations for this puzzle. One rational reason - in the sense of EUT - for the low demand might be that people anticipate ex post disaster relief by public or private organizations (Raschky and Weck-Hannemann 2007). One salient feature of disaster risk is that probabilities are usually very low and losses are very high. Given these properties of disaster risk, it is often argued that the willingness to pay for disaster insurance is too low, as people underweight lowprobability events, because "it can't happen to me."

However, the evidence is mixed. For example, Camerer and Kunreuther (1989) find experimental evidence that many subjects underweight or dismiss low-probability events, although others, often given additional information, might tend to overweight probabilities. McClelland et al. (1993) also find this bimodality in the probability weighting. On the other hand, Ganderton et al. (2000) only are able to confirm the overweighting, as evidenced by a high willingness to pay for insurance. Similarly, the experimental study of Laury et al. (2009) does not support the claim that the underinsurance phenomenon for low-probability events is due to an underweighting of loss probabilities. Much still needs to be learned about these types of probability biases.

Friedl et al. (2014) offer a new perspective on disaster insurance by focusing on the fact that individual risks are typically correlated. Since many peers are typically affected by the same disaster, social comparison may be an important factor affecting people's willingness to purchase insurance. This social comparison is modeled via preferences representing inequity aversion (Fehr and Schmidt 1999), where utility depends on both one's own payoff as well as the payoff of relevant peers. These preferences capture a type of modified loss aversion in social comparisons. In situations where the losses of individuals are correlated with those of relevant peers, strategic interaction becomes important.

In contrast to a situation with uncorrelated risks, buying no insurance is one of two Nash equilibria in pure strategies: for correlated disaster risk, people may prefer to remain uninsured. As the saying goes, "misery loves company." Or, put differently, community "bad luck" is somehow perhaps not as dire as one's own personal "bad luck."

Friedl et al. (2014) test their theory in the laboratory by comparing the willingness to pay of participants in treatments with both correlated and uncorrelated risks. They find a significant treatment effect, such that participants have a lower overall willingness to pay when the risks are correlated. This result that social comparisons matter in such uncertain situations supports several other recent experiments (e.g., Rohde and Rohde 2011; Linde and Sonnemans 2012). However, it seems apparent that peer effects may also work in the opposite direction. If my peers are purchasing insurance, I might regret not purchasing some for myself as well. It would be very interesting to investigate whether public market interventions (expectation management) can increase the demand for disaster insurance. For example, the insurance purchase of relevant peers or a critical mass of people may stimulate the demand decisions of others.

The second paper in this issue, by Hoy et al. (2014), deals with the low take-up rates for genetic tests, which the authors explain via ambiguity aversion. From a traditional EUT perspective, it would seem that genetic tests are a very attractive means for 
acquiring better information about the prospects of future individual health outcomes. The potential advantage for having such genetic tests is that people can adjust their behaviors to the information obtained from a genetic test, e.g. by taking specific preventive action or adjusting their surveillance behavior. Even in the absence of effective treatment options, other lifestyle choices like savings decisions, occupational decisions or the decision whether to have children or not might be influenced by information generated by genetic tests.

Hoy et al. (2014) start by analyzing how genetic testing influences individual beliefs from an ex ante point of view. Conditional on a positive or negative test result, individuals will adjust their probability beliefs of suffering from a genetic mutation or not. This updating takes into account the individuals' prior beliefs, and it realizes that genetic tests are typically not $100 \%$ accurate. At the time when a decision is made whether or not to undertake a genetic test, the probabilities of untoward consequences tend towards some population averages. Viewed ex ante, any potential updating of probability beliefs introduces a mean-preserving spread in the prior beliefs of the individual, compared to the status-quo. And any potential benefits of protecting oneself from potential harms are partly mitigated by the uncertainty inherent in the results of the genetic test itself.

Expected utility models suggest that costless unproductive genetic information has zero value, because EUT is linear in probabilities. However, if the information produced by the test is productive, then costless genetic information comes with the option value of adjusting one's actions based upon this information. This is in line with Savage's (1954) fundamental observation that information cannot be disadvantageous. By investigating three different measures of accuracy of the test, the authors find that improved accuracy leads to better decision-making and further enhances the value of information.

Hoy et al. (2014) leave the confines of EUT and apply the smooth ambiguityaversion model of Klibanoff et al. (2005), in a manner similar to Snow (2010). The authors focus on the incentives of an ambiguity-averse individual to take a genetic test. If genetic information is largely unproductive, then ambiguity aversion, as modeled in the sense of Klibanoff et al. (2005), implies a negative value of information due to the fact that mean-preserving spreads of probability beliefs affect an individual's welfare negatively under ambiguity aversion. Mechanically, this follows from the fact that the decision criterion is no longer linear in probabilities. An individual "lives through" the ambiguity by considering a genetic test. This negative sensation can be avoided by sticking to the current (known) beliefs and avoiding the genetic tests. The authors also derive comparative statics of the decision criterion under ambiguity aversion with respect to the accuracy of the genetic test.

Comparing both perspectives, ambiguity aversion is seen to be one possibility in explaining the low take-up rates of genetic tests. On a larger scale, the paper demonstrates the need to develop a behavioral understanding of the underlying decision processes before policy recommendations as related to genetic information can be developed.

The paper by Bommier and Le Grand (2014) deals with the annuity puzzle: why do many people seemingly under-invest in annuities? This puzzle arises as a contrast to the classical theoretical work of Yaari (1965). Using a life-cycle framework, Yaari's model predicts that risk-averse individuals would completely annuitize their wealth in order to 
eliminate lifespan uncertainty (so-called "longevity risk"), which results from the possibility of outliving one's own financial resources. At first glance, annuities seem desirable for risk-averse individuals concerned about their own well-being. However, this straightforward theoretical prediction is not compatible with observed low annuitization rates. Behavioral research has provided various reasons why people might not want to annuitize a significant share of their wealth. Loss aversion or framing effects may negatively affect the attractiveness of annuities. People may fear to lose any money invested in an annuity if they die far earlier than expected.

Bommier and Le Grand (2014) use a modified version of EUT to consider effects of an uncertain lifetime. They combine two preference-related arguments that together might explain why people may not want to annuitize at all. Bequest motives may explain why full annuitization is undesirable (Davidoff et al. 2005). However, as pointed out by Brown (2009) in an EUT-environment, such bequest motives alone cannot explain the extent of the low annuitization rates. Risk-averse individuals prefer shifting wealth from states with bad outcomes to states with good outcomes. Ideally, marginal utility for all states of the world is equalized. However, Brown et al. (2008) show that under a narrow investment framing, annuities may seem to increase risk instead of providing insurance. For individuals without bequest motives, the expected rate of return for an annuity under actuarially fair pricing and the expected rate of return for a risk-free bond would be equal, but the variance of returns is dominated by the bond. The annuity has the same average return but is more risky, since the tenor of annuity payments is risky.

The model of Bommier and Le Grand (2014) captures this idea, but in a different way. The authors consider both bequest motives and a concave lifetime utility function, in the spirit of Kihlstrom and Mirman (1974). Risk aversion for intertemporal (lifetime) risk and risk aversion for intratemporal risks are disentangled. Consequently, Bommier and Le Grand (2014) analyze the pure impact of an increase in intertemporal risk aversion on annuitization. As people in their model perceive a long life to be a good outcome and an early death to be a bad outcome, this setup captures the intuition that annuities might be viewed as risk increasing. Hence, low annuitization may be due to high intertemporal risk aversion, making other safe investments, such as bonds, more attractive for these individuals. In a calibrated model they show that lifetime risk aversion can partly explain low annuitization rates.

The last paper in this special issue, by Tausch et al. (2014), examines voluntary risk sharing with heterogeneous risks. They set up an experiment to deal with the basic question of whether adverse selection enhances or hampers potentially welfare-increasing risk sharing. Under adverse selection, consumers are assumed to have superior private risk-relevant information. As shown by the classic model of Rothschild and Stiglitz (1976), a market Nash-equilibrium will exist if insurers offer self-selection separating contracts, and if the good risks do not overly dominate the market.

Many empirical studies have attempted to measure the extent of and causes for adverse selection (e.g. Cohen and Siegelman 2010); but it is empirically challenging to disentangle adverse selection and moral hazard, as both problems lead to a positive correlation between the level of insurance coverage and the individual's degree of riskiness (e.g., Chiappori and Salanié 2000; Chiappori et al. 2006). Another implementation problem arises from the fact that most real-world settings do not reflect the 
same degree of homogeneity among individuals that exists in the Rothschild and Stiglitz (1976) model.

For example, Landsberger and Meilijson (1999) show that high risk individuals will only demand more coverage if their certainty equivalent for the uninsured risk is higher. Hence, when high risk consumers are less risk-averse than low risks, the positive correlation between insurance coverage and risk might not be observed or might even be reversed. The latter phenomenon, called "advantageous selection," is indeed observed in some insurance markets (Einav and Finkelstein 2011). These results imply that heterogeneity in preferences is as important as heterogeneity in risk in explaining insurance demand (Cutler et al. 2008).

Given the complexity and high number of (potentially) uncontrollable factors in empirical research, it is surprising that only few experimental papers deal with adverse selection issues in an insurance market. In their experiment, Tausch et al. (2014) control for both the risk and for the risk attitudes of the participants. Participants with perfect information about their own and other participants' risks must decide to what extent they want to share their risk with others (as a type of mutual insurance). In this setup, the authors explore whether risk-sharing decisions are consistent with predictions from standard game theory (Nash equilibrium) and whether participants with low risk are willing ex ante to subsidize others with less favorable risks.

When participants face equal risks, risk sharing is lower than predicted. However, results are generally in line with EUT under constant relative risk aversion. When risks of participants differ with respect to first-order stochastic dominance (essentially, the only type of difference considered by Rothschild and Stiglitz 1976), their experimental result supports an adverse-selection hypothesis. Low-risk participants are less willing to share their risk than high-risk participants. In contrast, in a treatment where the riskiness of participants differs according to mean-preserving spreads, there is no evidence for any adverse selection.

\section{Conclusions}

Whether it be social comparison, ambiguity aversion, lifetime vs. instantaneous risk aversion, or the classification of risk heterogeneity, individuals might respond differently to risk than predicted under EUT. The papers presented here all show how such behavioral influences can affect behavior. Of course, this is only a small set of such behavioral considerations.

Behavioral models of insurance come in many packages. Essentially, they can act as either complements to or substitutes for classical models based on EUT. This special issue shows how four seemingly diverse approaches can all lead to a somewhat similar conclusion: consumers often seem to under-invest in protecting themselves against risk.

Of course, other models, many of which were mentioned earlier, can lead to just the opposite observation: individuals might over-insure. Furthermore, by simply referring to "under-" and "over-" insuring, one must have a reference level of insurance in mind. Typically, this level is the one predicted by textbook EUT models. This once again illuminates the implied normative nature imbued into EUT choices. Who is to say that the levels of protection suggested by EUT are not themselves too much or too little? 
Of particular importance for future work might be the aggregate nature of behavioral distortions, and their effects on equilibrium in markets. If we do view EUT as "the norm," will individual deviations from EUT behavior be exacerbated in the aggregate, or will they tend to cancel one another out? Put differently, will market prices based upon EUT theories be relatively accurate, compared to actual prices? Will a general equilibrium model based on an EUT-preferenced representative agent be a good predictor of market prices? If so, should we be very concerned about the variations of each individual from this representative agent? Or we may consider a completely different setting in which individuals are all reasonably modelled as EUT maximizers, and yet aggregation does not seem to follow. Can behavior that seems "rational" at the individual level seem "irrational" in the aggregate? Or might it be the case that behavior is manipulable?

Ed Glaeser (2004) makes the interesting point that most economic decisions are situational - and insurance decisions would be no exception. Framing, social influence and default rules (the results of inaction) help to influence individual decisions. We see all of these aspects addressed in the various papers of this special issue. Of course, in the laboratory, we can largely control these settings. However, the setting in the field is also somewhat endogenous, in the sense that interested third parties might want to influence how we think of a certain decision. By providing "frames," by telling us "the right thing to do" and by presenting (perhaps) biased "facts," might not such third parties influence market decisions? The potential influence of such framing is summarized nicely by Thaler and Sunstein (2009). Indeed, if manipulation is possible in a laboratory setting, it is not that far-fetched to extend such manipulation to real-world markets. After all, who would want to buy health insurance if it included "death panels"?

The bigger picture, about which aspects of a more complicated decision problem are the most relevant, still remains. Likewise separating tastes from beliefs is still an issue in need of further study. While none of the papers presented here would seem to represent a generally applicable model to explain most decision making under risk, each model has something to offer. Each model shows how behavioral aspects might influence choice. Whether in the laboratory or within the restricted assumptions of a theoretical model, all of these frameworks control the background. As such, each paper helps us understand a bit more about real-world choices, but stops short of telling us how these results might be altered — or might be manipulated — in the field.

Acknowledgments The authors would like to thank Johannes Jaspersen and Richard Peter for helpful comments and suggestions. Any remaining errors and omissions are, as usual, the authors'.

\section{References}

Andersen, S., Harrison, G. W., Lau, M. I., \& Rutström, E. E. (2008). Eliciting risk and time preferences. Econometrica, 76(3), 583-618.

Barseghyan, L., Prince, J., \& Teitelbaum, J. C. (2011). Are risk preferences stable across contexts? Evidence from insurance data. American Economic Review, 101(2), 591-631.

Barseghyan, L., Molinari, F., O’Donoghue, T., \& Teitelbaum, J. (2013). The nature of risk preferences: Evidence from insurance choices. American Economic Review, 103(6). 
Bernoulli, D. (1738). "Specimen Theoriae Novae de Mensura Sortis." Commentarii Academiae Scientiarum Imperialis Petropolitanae. Trans. by L. Sommer, 1954, "Exposition of a New Theory on the Measurement of Risk." Econometrica, 22(1), 23-36.

Bommier, A., \& Le Grand, F. (2014). Too risk averse to purchase insurance? A theoretical glance at the annuity puzzle. Journal of Risk and Uncertainty, 48(2).

Borch, K. (1968). The economics of uncertainty. Princeton: Princeton University Press.

Brown, J. E. (2009). Understanding the role of annuities in retirement planning. In A. Lusardi (Ed.), Overcoming the saving slump: how to increase the effectiveness of financial education and saving programs (pp. 178-206). Chicago: University of Chicago Press.

Brown, J. E., Kling, J. R., Mullainathan, S., \& Wrobel, M. V. (2008). Why don't people insure late-life consumption? A framing explanation of the under-annuitization-puzzle. American Economic Review, 98(2), 304-309.

Buckley, N. J., Cuff, K., Hurley, J., McLeod, L., Nuscheler, R., \& Cameron, D. (2012). Willingness-to-pay for parallel private health insurance: evidence from a laboratory experiment. Canadian Journal of Economics, 45(1), 137-166.

Camerer, C. F., \& Kunreuther, H. (1989). Decision processes for low probability events: policy implications. Journal of Policy Analysis and Management, 8(4), 565-592.

Chiappori, P.-A., \& Salanié, B. (2000). Testing for adverse selection in insurance markets. Journal of Political Economy, 108(1), 56-78.

Chiappori, P.-A., Jullien, B., Salanié, B., \& Salanié, F. (2006). Asymmetric information in insurance: general testable implications. RAND Journal of Economics, 37(4), 783-798.

Cohen, A., \& Einav, L. (2007). Estimating risk preferences from deductible choices. American Economic Review, 97(3), 745-788.

Cohen, A., \& Siegelman, P. (2010). Testing for adverse selection in insurance markets. Journal of Risk and Insurance, 77(1), 39-84.

Crocker, K. J., \& Morgan, J. (1998). Is honesty the best policy? Curtailing insurance fraud through optimal incentive contracts. Journal of Political Economy, 106(2), 355-375.

Cutler, D. M., Finkelstein, A., \& McGarry, K. (2008). Preference heterogeneity and insurance markets: explaining a puzzle of insurance. American Economic Review, 98(2), 157-162.

Davidoff, T., Brown, J. R., \& Diamond, P. A. (2005). Annuities and individual welfare. American Economic Review, 95(5), 1573-1590.

Drèze, J., \& Schokkaert, E. (2013). Arrow's theorem of the deductible: moral hazard and stop-loss in health insurance. Journal of Risk and Uncertainty, 47(2), 147-163.

Einav, L., \& Finkelstein, A. (2011). Selection in insurance markets: theory and empirics in pictures. Journal of Economic Perspectives, 25(1), 115-138.

Einav, L., Finkelstein, A., \& Cullen, M. R. (2010). Estimating welfare in insurance markets using variation in prices. Quarterly Journal of Economics, 125(3), 877-921.

Einav, L., Finkelstein, A., Pascu, I., \& Cullen, M. R. (2012). How general are risk preferences? Choices under uncertainty in different domains. American Economic Review, 102(6), 2606-2638.

Fehr, E., \& Schmidt, K. M. (1999). A theory of fairness, competition, and cooperation. Quarterly Journal of Economics, 114(3), 817-868.

Finkelstein, A., \& McGarry, K. (2006). Multiple dimensions of private information: evidence from the longterm care insurance market. American Economic Review, 96(4), 938-958.

Friedl, A., Lima de Miranda, K., \& Schmidt, U. (2014). Insurance demand and social comparison: An experimental analysis. Journal of Risk and Uncertainty, 48(2).

Ganderton, P. T., Brookshire, D. S., McKee, M., Steward, S., \& Thurston, H. (2000). Buying insurance for disaster-type risks: experimental evidence. Journal of Risk and Uncertainty, 20(3), 271-289.

Glaeser, E. (2004). Psychology and the market. American Economic Review: Papers and Proceedings, 94(2), $408-413$.

Gollier, C. (1996). Optimal insurance for approximate losses. Journal of Risk and Insurance, 63(3), 369-380.

Harrison, G. W., \& List, J. A. (2004). Field experiments. Journal of Economic Literature, 42(4), 1013-1059.

Harrison, G. W., \& Martinez-Corea, J. (2012). Behavioral insurance: a survey. Working paper: Georgia State University.

Harrison, G. W., \& Rutström, E. E. (2009). Expected utility theory and prospect theory: one wedding and a decent funeral. Experimental Economics, 12(2), 133-158.

Hershey, J. C., \& Schoemaker, P. J. H. (1980). Risk taking and problem context in the domain of losses: an expected utility analysis. Journal of Risk and Insurance, 47(1), 111-132.

Hoy, M., Peter, R., \& Richter, A. (2014). Take-up for genetic tests and ambiguity. Journal of Risk and Uncertainty, 487(2). 
Kihlstrom, R. E., \& Mirman, L. J. (1974). Risk aversion with many commodities. Journal of Economic Theory, 8(3), 361-388.

Klibanoff, P., Marinacci, M., \& Mukerji, S. (2005). A smooth model of decision making under ambiguity. Econometrica, 73(6), 1840-1892.

Kusev, P., van Schaik, P., Ayton, P., Dent, J., \& Chater, N. (2009). Exaggerated risk: prospect theory and probability weighting in risky choice. Journal of Experimental Psychology: Learning, Memory, and Cognition, 35(6), 1487-1505.

Landsberger, M., \& Meilijson, I. (1999). A general model of insurance under adverse selection. Economic Theory, 14(2), 331-352.

Laury, S. K., McInnes, M. M., \& Swarthout, J. T. (2009). Insurance decisions for low-probability losses. Journal of Risk and Uncertainty, 39(1), 17-44.

Linde, J., \& Sonnemans, J. (2012). Social comparison and risky choices. Journal of Risk and Uncertainty, 44(1), 45-72.

Machina, M. (1995). Non-expected utility and the robustness of the classical insurance paradigm. Geneva Papers on Risk and Insurance Theory, 20(1), 9-50.

Manski, C. F. (2004). Measuring expectations. Econometrica, 72(5), 1329-1376.

McClelland, G. H., Schulz, W. D., \& Coursey, D. L. (1993). Insurance for low-probability hazards: a bimodal response to unlikely events. Journal of Risk and Uncertainty, 7(1), 95-116.

Mehra, R., \& Prescott, E. C. (1985). The equity premium: a puzzle. Journal of Monetary Economics, 15(2), 145-161.

Nell, M., Richter, A., \& Schiller, J. (2009). When prices hardly matter: incomplete insurance contracts and markets for repair goods. European Economic Review, 53(3), 343-354.

Picard, P. (1996). Auditing claims in the insurance market with fraud: the credibility issue. Journal of Public Economics, 63(1), 27-56.

Postlewaite, A., \& Schmeidler, D. (2012). Rationality and uncertainty. Revisita Internazionale di Scienze Sociali, 2012(3), 289-294.

Rabin, M. (2000). Risk aversion and expected-utility theory: a calibration theorem. American Economic Review, 68(5), 1281-1292.

Raschky, P. A., \& Weck-Hannemann, H. (2007). Charity hazard - a real hazard to natural disaster insurance? Environmental Hazards, 7(4), 321-329.

Rohde, I. M. T., \& Rohde, K. I. M. (2011). Risk attitudes in a social context. Journal of Risk and Uncertainty, 43(3), 205-225.

Rothschild, M., \& Stiglitz, J. (1976). Equilibrium in competitive insurance markets: an essay on the economics of imperfect information. Quarterly Journal of Economics, 90(4), 629-649.

Samuelson, L. (2005). Economic theory and experimental economics. Journal of Economic Literature, 43(1), 65-107.

Savage, L. J. (1954). The foundations of statistics. New York: Wiley.

Schoemaker, P. J. H., \& Kunreuther, H. C. (1979). An experimental study of insurance decisions. Journal of Risk and Insurance, 46(4), 603-618.

Slovic, P. (1987). Perception of risk. Science, 236(4799), 280-285.

Snow, A. (2010). Ambiguity and the value of information. Journal of Risk and Uncertainty, 40(2), $133-145$.

Starmer, C. (2000). Developments in non-expected utility theory: the hunt for a descriptive theory of choice under risk. Journal of Economic Literature, 38(2), 332-382.

Sydnor, J. (2010). (Over)insuring modest risks. American Economic Journal: Applied Economics, 2(4), 177199.

Tausch, F., Potters, J., \& Riedl, A. (2014). An experimental investigation of risk sharing and adverse selection. Journal of Risk and Uncertainty, 48(2).

Thaler, R. H., \& Sunstein, C. R. (2009). Nudge: improving decisions about health, wealth and happiness. London: Penguin.

Viscusi, W. K., \& Born, P. H. (2005). Damages caps, insurability, and the performance of medical malpractice insurance. Journal of Risk and Insurance, 72(1), 23-43.

Wakker, P., Thaler, R., \& Tversky, A. (1997). Probabilistic insurance. Journal of Risk and Uncertainty, 15(1), $7-28$.

Yaari, M. E. (1965). Uncertain lifetime, life insurance, and the theory of the consumer. Review of Economic Studies, 32(2), 137-150. 